\title{
Konstruksi Relasi Gender Suku Bugis pada Karakter Emma dalam Film Athirah (2016)
}

\section{Construction of Gender Relations Bugis Tribe On the Emma Character in Athirah Movie (2016)}

\author{
Nurul Mutia Diansyah, Riksa Belasunda \& Teddy Hendiawan \\ Universitas Telkom, Bandung, Jawa Barat, Indonesia \\ email : muthi1412@gmail.com,riksab@telkomuniversity.ac.id, \\ teddyhendiawan@telkomuniversity.ac.id
}

\begin{abstract}
Abstrak
Film yang mengangkat budaya suku Bugis dan kental tentang relasi gender adalah film Athirah yang menceritakan tentang ketegaran perempuan Bugis dalam keluarga sangat berharga. Isu perempuan tidak pernah habis dibicarakan terkait dengan kesetaraan maupun ketidakadilan gender dan paham patriarki di Indonesia bahwa kekuasaan laki-laki yang menentukan keputusan kehidupan perempuan. Pola relasi gender terdiri dari kekuasaan dan status, komunikasi non verbal, serta pembagian kerja. Penelitian ini bertujuan untuk memahami konstruksi relasi gender dan mitos suku Bugis dalam karakter Emma pada mise en scene film Athirah. Penelitian ini menggunakan kualitatif, pendekatan cultural studies dengan menggunakan analisis semiotika Roland Barthes untuk menganalisis objek yang diteliti. Adapun hasil dari penelitian ini ialah relasi gender dalam film Athirah dikontruksi oleh budaya dari segi ideologi patriarki dan ideologi feminisme. Kesimpulannya adalah konstruksi relasi gender dalam film Athirah ini tersusun dari budaya, ekonomi, serta lingkungan fisik suatu tempat yang saling berkaitan.
\end{abstract}

Kata kunci: konstruksi, relasi gender, film athirah

\begin{abstract}
The film raised its bugis culture and viscid about gender relations is a film Athirah share obstinacy women bugis in family highly prized. Women issues it never runs out discuss relating to or gender equality injustice and understand the patriarch in Indonesia that power male determine the decision of female life. The gender relations consisting of power and status, communication non verbal, and the distribution of work. This study aims to understand construction gender relations and myths the tribe of bugis in character Emma on mise en scene film Athirah. Qualitative was used in the study, the approach of cultural studies with using analysis logician Roland Barthes to analyze is as high as object. As for the result of the study is gender relations in a film Athirah construction by the culture in terms of ideology the patriarch and ideology of feminism. The conclusion is the construction of gender relations in the Athirah film is composed of cultural, economic, and physical environments that are interrelated.
\end{abstract}

Keywords: construction, gender relations, film athirah

\section{PENDAHULUAN}

Film adalah sebuah media audio visual yang bisa dinikmati oleh siapapun. Film pada umumnya menggambarkan tentang fiktif atau khayalan maupun non fiktif atau nyata. Selain membentuk konstruksi masyarakat akan suatu hal, film juga merupakan rekaman realitas yang tumbuh dan berkembang dalam masyarakat dan kemudian memproyeksikannya ke atas layar (Sobur, 2017). Dalam hal lain, konstruksi dalam relasi gender tersusun dari agama, budaya, ekonomi, politik, atau lingkungan fisik suatu tempat yang saling berkaitan. Sehingga jika 
tidak ada semua unsur pembentuk relasi gender akan terjadi ketidakseimbangan pola relasi gender. Gender adalah persoalan budaya yang mengatur konstruksi sosial lelaki, perempuan, dan hubungan-hubungan sosial di antara mereka. Bahkan dari itu, persamaan gender telah menjadi salah satu isu yang dipertimbangkan dalam pembangunan berkelanjutan di mana kesetaraan gender merupakan persyaratan utama untuk mewujudkan dunia yang adil dan berkelanjutan (United Nations, 2014).

Pada era reformasi tahun 1998 sampai dengan sekarang banyak film Indonesia yang mengangkat tentang gender (Kurnia, 2017). Film-film tersebut membahas ketidakadilan dan kesetaraan gender. Isu perempuan tidak pernah habis dibicarakan terkait dengan kesetaraan maupun ketidakadilan gender dan paham patriarki di Indonesia bahwa kekuasaan laki-laki yang menentukan keputusan kehidupan perempuan. Film-film tersebut juga menampilkan ketidakseimbangan pola relasi gender antara suami istri dalam keluarga. Pola relasi gender terdiri dari segi kekuasaan dan status, komunikasi non verbal, serta pembagian kerja antara laki-laki dan perempuan.

Film Indonesia pada abad ke-20 mulai mengangkat unsur budaya suatu daerah untuk membuat cerita film lebih menarik. Hal tersebut menarik perhatian para sineas dan penonton karena mengangkat sisi kehidupan yang berbeda. Salah satu film yang mengangkat budaya suku bugis dan kental tentang relasi gender adalah film "Athirah" yang disutradarai oleh Riri Riza. Secara singkat film tersebut berlatarkan budaya suku Bugis yang menceritakan bahwa ketegaran perempuan Bugis dalam keluarga sangat berharga. Selain itu ada banyak penelitian-penelitian terdahulu yang terkait dengan penelitian ini di antaranya penelitian dari Oláh dkk (2014) yang menggambarkan hubungan antara peran baru wanita dan pria dan dinamika keluarga serta implikasi dari perubahan struktur gender pada transisi menjadi orang tua. Menurut Beaujot dkk (2017) saat ini perbedaan gender cenderung menurun, hanya saja perbedaan gender masih terkesan kuat misalnya dalam kehidupan dengan anak-anak, dengan wanita di usia muda dan wanita tidak dalam pasangan lebih mungkin daripada pria yang hidup bersama anak-anak. Lebih lanjut, sebuah kajian tentang peran perempuan dalam sebuah film diangkat oleh Murphy (2015) dengan judul "The role of women in film: Supporting the men -- An analysis of how culture influences the changing discourse on gender representations in film" hasilnya yaitu isu gender dan stereotip rasial dalam film tidak mati, bahkan terdapat kemajuan di mana demografi penonton dan preferensi aktual gender dipertimbangkan lebih serius dalam keputusan produksi untuk mempengaruhi representasi yang lebih positif dan untuk lebih inklusif.

Berdasarkan uraian di atas, penulis tertarik untuk mengangkat topik tentang relasi gender suku Bugis pada karakter Emma dalam film Athirah karya Riri Riza tersebut. Dengan menganalisis film tersebut, penulis berharap dapat memahami relasi gender suku Bugis dan mitos melalui mise en scene dengan semiotika Roland Barthes. Oleh karena itu, topik penelitian ini adalah "Konstruksi Relasi Gender Suku Bugis pada Karakter 
Emma dalam Film Athirah".

\section{METODE PENELITIAN}

Penelitian ini merupakan penelitian kualitatif dengan menggunakan pendekatan cultural studies dan analisis semiotika Roland Barthes untuk menganalisis objek yang diteliti. Secara khusus, Barthes menerapkan metode semiotika untuk menerangi berbagai gejala budaya hingga akhirnya ia sampai pada argumen bahwa semua teks dikonstruksi lewat tanda-tanda dalam gugus konteks sosial. Yang menjadi pokok pikiran Barthes adalah peran tanda-tanda dalam menghasilkan makna dan membingkai cara pembacaan teks (Barker, 2014). Barthes (2007) menggunakan pengembangan teori tanda de Saussure (penanda dan petanda) sebagai upaya menjelaskan bagaimana kita dalam kehidupan bermasyarakat didominasi oleh konotasi. Konotasi adalah pengembangan segi petanda (makna atau isi suatu tanda) oleh pemakain tanda sesuai dengan sudut pandangnya (Hoed, 2014). Tanda konotatif tidak sekedar memiliki makna tambahan namun juga mengandung kedua bagian tanda denotatif yang melandasi kebenarannya (Sobur, 2017). Denotasi biasanya dimengerti sebagai sebuah makna deskriptif, bahkan kadang kala juga dirancukan dengan referensi atau acuan (Sobur, 2017).

Menurut Roland Barthes, konotasi identik dengan operasi ideologi, yang disebutnya sebagai 'mitos', dan berfungsi untuk mengungkapkan dan memberikan pembenaran bagi nilai-nilai dominan yang berlaku dalam suatu periode tertentu (Sobur, 2017). Mitos dibangun oleh suatu rantai pemaknaan yang telah ada sebelumnya atau, dengan kata lain, mitos adalah juga suatu sistem pemaknaan tataran kedua. Meski mitos merupakan konstruksi sosial, mitos seperti kebenaran-kebenaran yang diwariskan dan tertanam dalam nalar sehari-hari. Dengan demikian, konsep mitos hampir sama dengan konsep ideologi, yang bekerja pada level konotasi (Rachmawati \& Nurrachmi, 2012). Sehingga mitos membuat pandangan yang sudah ada tidak bisa diubah karena tujuan mitos sendiri untuk memberikan pembenaran terhadap sesuatu pada waktu tertentu.

\section{HASIL DAN PEMBAHASAN}

\subsection{Hasil Penelitian}

Penelitian ini bertujuan untuk memahami konstruksi relasi gender dan mitos suku Bugis dalam karakter Emma pada mise en scene film Athirah. Berikut beberapa adegan film yang berhubungan dengan relasi gender dan analisisnya:
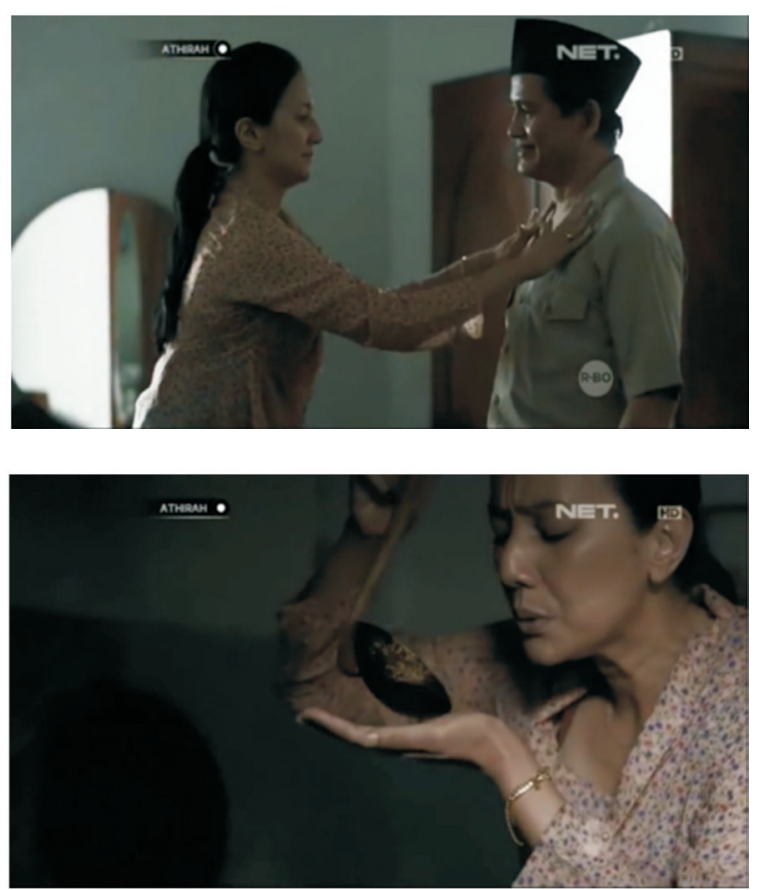

Gambar 3.1. Screenshot Adegan 10 Shot 35 dan 36, Sumber: Film Athirah

Jurnal Penelitian Pendidikan 


\begin{tabular}{ll}
\hline Analisis Visual dari & Relasi gender antara Emma dan Bapak dari adegan di atas terlihat jelas dari \\
Relasi Gender & pergerakan pemain yang di mana memperlihatkan Emma yang merapikan \\
& baju Bapak menunjukkan kasih sayang dan perhatian sebagai seorang istri. \\
& Selain pergerakan pemain, kostum yang digunakan juga menunjukkan \\
& bedanya kedudukan dan peran antara Emma dan Bapak. Seperti pepatah \\
& orang Bugis, wilayah perempuan adalah sekitar rumah, sedangkan ruang \\
& gerak kaum pria “menjulang hingga ke langit”. Kata bijak tersebut juga \\
& menjelaskan peran laki-laki dan perempuan dalam kehidupan rumah tangga. \\
& Pola relasi gender pada adegan di atas menunjukkan pembagian kerja bagi \\
& perempuan Bugis. Pembagian kerja dalam pola relasi gender termasuk ade' \\
& pangngaderreng (adat istiadat orang bugis 'panca norma') dalam budaya \\
& suku Bugis. Sehingga tidak ada kesetaraan bahkan ketidakadilan gender \\
& dari adegan di atas. \\
\hline Perempuan Bugis mancaji missing dapureng 'mengetahui area dapur' \\
menggambarkan dengan jelas perempuan Bugis harus bisa memasak dan \\
Mitos & melaksanakan tugas-tugas rumah tangga, hal tersebut terlihat Emma sedang \\
& mencicipi masakan menunjukkan perasaan sebagai seorang istri dan ibu \\
& bagi anak-anaknya. \\
\hline
\end{tabular}

\subsection{Pembahasan}

Menurut Azra (2008) secara etimologi (bahasa), kata "gender" berasal dari bahasa Inggris, gender berarti "jenis kelamin". Sedangkan secara terminologi (istilah), gender adalah suatu konsep kultural yang berupaya membuat pembedaan (distinction) dalam hal peran, perilaku, mentalitas, dan karakteristik emosional antara lakilaki dan perempuan yang berkembang dalam masyarakat. Adapun relasi gender merupakan konsep hubungan sosial antara laki-laki dan perempuan berdasar kualitas, skill, peran dan fungsi dalam konvensi sosial yang selalu berkembang (Umar, 1999). Umar (2012) mendefinisikan relasi gender sebagai hubungan timbal balik antara satu pasangan dan pasangan lainnya, seperti hubungan antara suami dan istri. Firdaus (2015) mendefinisikan relasi gender sebagai akibat dari ketidakseataraan gender di setiap tempat dan/ atau daerah karena erat kaitannya dengan berbagai factor seperti faktor ekologi, budaya dan agama. Di sisi lain menurut Hasanah \& Musyafak (2017) bahwa munculnya isu ketidakadilan gender atau diskriminasi gender diakibatkan oleh proses konstruksi sosial di masyarakat. Lebih detailnya menurut Fakih (1999) bahwa ketidakadilan gender tersebut antara lain: 1) marginalisasi perempuan; 2) penempatan perempuan pada subordinat; 3) stereotype perempuan; 4) kekerasan (violence) terhadap perempuan; dan 5) beban kerja tidak proposional.

Keluarga adalah ibarat hewan berdarah panas yang dapat memelihara temperatur tubuhnya agar tetap konstan walaupun kondisi lingkungan berubah (Parsons \& R. F. Bales, 1976). Dalam teori ini, pembagian peran secara seksualadalahwajar. Suamimengambil peran instrumental, membantu memelihara sendi-sendi masyarakat dan keutuhan fisik keluarga dengan jalan menyediakan bahan makanan, tempat pelindungan dan menjadi penghubung keluarga dengan dunia luar, the world outside the home. Sementara isteri mengambil peran ekspresif membantu mengentalkan hubungan, memberikan dukungan emosional dan pembinaan kualitas yang menopang keutuhan keluarga serta menjamin kelancaran urusan rumah tangga. Menurut teori ini, jika terjadi tumpang tindih 
dan penyimpangan fungsi antara satu dan lainnya, maka sistem keutuhan keluarga akan mengalami ketidakseimbangan. Dengan kata lain kerancuan peran gender akan mengakibatkan ketidakharmonisan dalam rumah tangga atau bahkan perceraian.

Menurut Talcot Pasons dan Robert Bales, bahwa relasi gender dalam institusi keluarga lebih merupakan pelestarian keharmonisan ketimbang bentuk persaingan. Pola relasi gender dalam konteks teori ini ditentukan oleh faktor. Pertama, kekuasaan dan status. Laki-laki memiliki kekuasaan dan status lebih tinggi dibandingkan dengan perempuan. Perempuan dinilai mempunyai perilaku lembut dan laki berpenampilan dan berperilaku tegar dan jantan sehingga memiliki kekuasaan dan status lebih besar. Kedua, komunikasi non verbal. Komunikasi antara laki-laki dan perempuan dalam masyarakat berlangsung dalam suasana yang disebut Nancy Henlley sebagai kemampuan kurang (less powerful) bagi perempuan dan kemampuan lebih (more powerful) bagi laki-laki. Dalam suasana selalu dikontrol, perempuan dengan subordinasinya menampilkan diri dengan serba hati-hati, sedangkan laki-laki dengan otoritas yang dimiliki menampilkan diri lebih terbuka dan komunikatif. Sehingga dalam relasi gender laki-laki memiliki skor lebih unggul dalam penentuan norma-norma masyarakat. Ketiga, pembagian kerja. Relasi kuasa dan status yang berbeda antara laki-laki dan perempuan menjadi dasar pembagian kerja dalam rumah tangga. Dalam masyarakat tradisional maupun modern, kondisi ini tetap terjadi walaupun dalam konteks yang berbeda. Urusan-urusan produktif seakan- akan menjadi tugas laki-laki dan reproduktif menjadi tugas perempuan. Laki-laki dikonsepkan mengurusi urusan publik dan perempuan urusan domestik. (Narwoko \& Suyanto, 2010).

Penulis mendapatkan pola relasi gender perempuan suku Bugis dalam karakter Emma pada film Athirah yang dominan dari segi pembagian kerja seperti mancaji missing dapureng 'mengetahui area dapur'menggambarkan dengan jelas perempuan Bugis harus bisa memasak dan melaksanakan tugas-tugas rumah tangga, mancaji imattaro 'menjadi pengelola keuangan' yang di mana perempuan Bugis harus bisa mengatur keuangan dalam rumah tangga, menyimpan, dan membelanjakannya dengan teratur, mancaji makkunrai 'menjadi seorang perempuan' yang menekankan peran perempuan Bugis untuk memelihara dirinya agar terhindar dari rasa malu. Peran perempuan Bugis lainnya mancaji baliperi' 'menemani dalam semua kondisi' yang di mana perempuan Bugis harus menjadi pasangan yang baik bagi suaminya dalam suka maupun duka. Selain itu pola relasi gender juga terdapat kekuasaan dan status serta komunikasi non verbal.

Dari penelitian ini, penulis juga menemukan keseimbangan dan ketidak seimbangan pola relasi gender. Keseimbangan pola relasi gender terlihat dalam pembagian kerja yang menggambarkan dengan jelas perempuan Bugis dalam ruang domestiknya (rumah), serta kekuasaan dan status yang menggambarkan perempuan Bugis menutupi rasa malu dirinya yang tidak datang ke acara pernikahan bersama suaminya. Sedangkan ketidakseimbangan pola relasi 
gender terlihat dalam kekuasaan dan status yang menggambarkan perempuan Bugis memiliki kekuasaan terutama dalam ruang domestiknya (rumah), serta komunikasi non verbal yang menggambarkan perempuan Bugis lebih komunikatif dan terbuka yang biasanya perempuan Bugis lebih berhati-hati dalam bertindak. Jika dilihat dari budaya patriarki, kekuasaan dipihak laki-laki yang menguasai perempuan sehingga membuat perempuan menjadi tunduk kepada laki-laki. Mitos yang penulis temukan dalam film Athirah, perempuan Bugis dominan memiliki kekuasaan dalam ruang domestiknya (rumah) yang di mana Emma mengusir Bapak dari rumah karena Emma tidak dinafkahi lahir dan batin. Hal tersebut sesuai dengan pepatah orang Bugis yaitu perempuan Bugis massipa' arungingi 'bersifat seperti raja' menggambarkan dengan jelas perempuan Bugis selalui ingin berkuasa serta hal tersebut termasuk ideologi feminisme.

\section{KESIMPULAN}

Jadi dapat ditarikkesimpulanbahwakonstruksi relasi gender dalam film Athirah ini tersusun dari budaya, ekonomi, serta lingkungan fisik suatu tempat yang saling berkaitan. Jika dilihat ideologi patriarki termasuk dari segi budaya, penulis menemukan pola relasi gender pada budaya suku Bugis termasuk dalam ade' pangngaderreng (adat istiadat orang Bugis 'panca norma') karena sudah ada dan berlaku dari zaman dahulu. Sedangkan dari segi ekonomi, penulis menemukan pola relasi gender pada film Athirah yang dominan ekonomi menengah ke atas terlihat dari properti yang digunakan pada tahun tersebut. Dan yang terakhir dari segi faktor lingkungan di masyarakat Bugis, penulis menemukan pola relasi gender pada film Athirah yang dimana pada zaman tersebut suami memiliki banyak istri ialah suatu budaya karena mengikuti syariat islam 'suami boleh mempunyai banyak (empat) istri'. Maka dari itu relasi gender dalam budaya suku Bugis pada film Athirah dipengaruhi oleh ekonomi, lingkungan, serta budaya pada zaman tersebut. Sutradara film ini merepresentasikan sesuai dengan budaya suku Bugis dan novel Athirah karangan Alberthiene Endah bahwa ketegaran perempuan Bugis dalam keluarga sangat berharga.

\section{DAFTAR RUJUKAN}

Azra, A. (2008). Kajian Tematik al-Qur'an tentang Kemasyarakatan. Bandung: Angkasa.

Barker, C. (2014). Kamus Kajian Budaya. Yogyakarta: PT. Kanisius.

Barthes, R. (2007).Membedah Mitos-Mitos Budaya Massa: Semiotika Atau Sosiologi Tanda, Simbol dan Representasi. Yogyakarta: Jalasutra.

Beaujot, Roderic., Liu, Jianye\&Ravanera, Zenaida. (2017). Gender inequality in the family setting. Canadian Studies in Population 44,1-2, hlm. 1-13

Fakih, M. (1996). Analisis Gender dan Transformasi Sosial. Yogyakarta: Pustaka Pelajar.

Firdaus, J. (2015). Relasi Gender dalam Keluarga; Islam dan Feminisme. Diakses dari kompasiana pada25 November 2018.

Hasanah, U \& Musyafak, N. (2017). Gender and Politics: Keterlibatan Perempuan dalam Pembangunan Politik. SAWWA,12 (3), hlm. 409-432.

Hoed, Benny H. (2014). Semiotik dan Dinamika Sosial Budaya. Depok: Komunitas Bambu. 
Kurnia, N. (2017). Consuming Gender and Disability in Indonesian Film. Diakses dari https://www.researchgate. net/publication/326139992_CONSUMING_GENDER_AND_DISABILITY_IN_INDONESIAN_ FILM pada 25 November 2018.

Narwoko, J. D\&Suyanto, B. 2010. Sosiologi: Teks Pengantar dan Terapan. Jakarta: Pernada Media.

Murphy, J. N. (2015). The role of women in film: Supporting the men: An analysis of how culture influences the changing discourse on gender representations in film. Journalism Undergraduate Honors Theses, 2 , hlm 1-35.

Oláh, L. S., Rudolf, R\& Irena E. K. (2014). The new roles of men and women and implications for families and societies.A project funded by European Union's Seventh Framework Programme under grant agreement no. 320116, hlm. 1-61.

Parsons, T \& R. F. Bales. (1976). Family: socialization and Interaction Process. London: Routledge, Kegan \& Paul.

Rachmawati, A. \& Nurrachmi, S. (2012). Cultural Studies: Analisis Kuasa Atas Kebudayaan. Surabaya: UPN Veteran.

Sobur, A. (2017). Semiotika Komunikasi. Bandung: PT. Remaja Rusdakarya.

Umar, N.(1999). Argumen Kesetaraan Gender Perspektif Alquran. Jakarta: Paramadina.

Umar, N. (2012).Relasi Gender Makrokosmos. Diakses dari Republika Online pada 25 November 2018.

United Nations. (2014). The World Survey on the Role of Women in Development on the gender equality and sustainable development. United State: United Nations publication 